\section{Innovación, imagen y realidad: ¿Sólo una cuestión de tecnologías?}

Daniel Tubío ${ }^{(*)}$

\footnotetext{
(*) Artista visual. Egresado de la Escuela Nacional de Bellas Artes Manuel Belgrano. Es profesor en la Facultad de Diseño y Comunicación de la Universidad de Palermo y en la Facultad de Arquitectura, Diseño y Urbanismo (UBA). Dirige su propio Taller de Fotografía.
}

Resumen: Este trabajo propone un recorrido a través de los usos históricos de los dispositivos de creación y reproducción de imágenes y a la vez una reflexión alrededor de dos tópicos: la desmaterialización de la imagen como objeto y el uso de esa imagen desmaterializada como elemento de archivo que ocupa el lugar de la memoria. A partir de allí se intenta elaborar algunas hipótesis acerca del impacto de las nuevas tecnologías en relación con la imagen.

El desarrollo histórico de las modalidades de representación de lo real y la idea de desmaterialización de la imagen/objeto parten de algunos planteos propuestos por Philippe Dubois en Máquinas de imágenes: una cuestión de línea general (2000). De su lectura, sumada a la lectura de algunos otros autores -John Berger entre ellos- surge la reflexión y la hipótesis de la captura fotográfica digital como prótesis de la memoria.

Palabras claves: fotografía - memoria - prótesis - realidad virtual - tecnología.

[Resúmenes en inglés y portugués en la página 146]

\title{
Introducción
}

"He estado en la fotografía, la he rondado y he pensado en ella durante veinte años. Y quizás ahora sepa ya lo suficiente para empezar a considerar qué es la fotografía."

La intención de este trabajo es tratar de establecer una línea de desarrollo histórico en cuanto a las modalidades de representación de lo real tomando como punto de partida la aparición o, para ser más precisos, el uso sistemático con fines artísticos de los sistemas ópticos de formación de imágenes con luz utilizados como apoyo para el dibujo y la pintura, pasando por la aparición de la fotografía y el cine para llegar hasta la incipiente y vertiginosa tecnología de la imagen digital y de la denominada realidad virtual. A través de este recorrido se pretende hacer una reflexión alrededor de dos tópicos que creemos están íntimamente relacionados: por un lado, la progresiva desmaterialización de la imagen como objeto y, por el otro, el uso de esa misma imagen desmaterializada como elemento de archivos supernumerarios que en cierta medida parecen suplantar a la memoria. De la conjunción 
entre este recorrido histórico y las relaciones anteriormente propuestas se intentará elaborar algunas conclusiones acerca del rol de las nuevas tecnologías en relación con la imagen y se plantearán algunas hipótesis sobre las consideraciones que deberíamos hacer aquellos que usamos las imágenes como forma de expresión artística, los que nos dedicamos a la enseñanza de alguna disciplina que implique el uso de imágenes y quienes se dedican al pensamiento crítico alrededor del tema.

No siendo quien escribe un teórico sino más bien un practicante de la imagen, la intención final de este artículo no es dar respuestas sobre el tema sino más bien compartir dudas y poner sobre el papel preguntas surgidas de la práctica -artística y docente- para promover inquietudes alrededor de nuestra relación con la imagen, sobre todo en aquellos que se dedican a pensar el mundo desde distintas disciplinas. Sería interesante sumar voluntades para intentar develar, desde nuestra realidad como país, cuál es la función que cumple la imagen en los diversos campos en la sociedad, desde la publicidad hasta la fotografía doméstica, pasando por el periodismo y el arte. Y crear un espacio de reflexión permanente para posibilitar la definición de una "imagen argentina" -si es que una cosa semejante existe- en el más amplio de los sentidos, desde la teoría y por supuesto y sobre todo, desde la praxis. El desarrollo histórico de las modalidades de representación de lo real y la idea de desmaterialización de la imagen/objeto parten de algunos planteos propuestos por Philippe Dubois en Máquinas de imágenes: una cuestión de línea general (2000). De su lectura, sumada a la lectura de algunos otros autores -John Berger entre ellos- surge la reflexión y la hipótesis de la captura fotográfica digital como prótesis de la memoria desarrollada en la parte final de este trabajo.

\section{Tres casos reveladores}

A veces la observación de determinados hábitos sociales nos permite advertir detalles que funcionan como índice de los procesos que está viviendo la sociedad. Por otra parte, algunas ficciones nos develan fenómenos que están ocurriendo y que tal vez pasan desapercibidos en la observación directa de la realidad. Ambas instancias -la observación y la lectura de ficciones- funcionan en este caso como disparadores de la reflexión.

\section{Caso 1: Cierre de curso avanzado de fotografía, FADU, UBA, diciembre 2005}

Un alumno expone un trabajo con el que intenta dar cuenta del deterioro que sufre la naturaleza por la intervención irracional del hombre y su cultura. El trabajo está compuesto por doce fotografías montadas sobre un panel. En el mismo se intercalan tomas directas hechas sobre objetos de la naturaleza (básicamente formas vegetales) y tomas directas hechas sobre pequeños objetos que podrían agruparse bajo la categoría de "deshechos industriales" (pilas, fragmentos de vidrio, etc.), dispuestos de forma tal que asemejan bosques o cultivos vistos desde el aire. Las tomas mencionadas en primer lugar fueron realizadas en diversos escenarios naturales y las mencionadas en segunda instancia se armaron para ser fotografiadas posteriormente. Lo interesante es que cuando el autor presenta su trabajo, ordena su discurso acerca de las imágenes nominando a las primeras (fotos de la naturaleza) como "las fotos reales" y a las segundas (fotos de deshechos) como "las otras". Es decir que, desde su conceptualización de lo real, les otorga realismo en función de los objetos fotografiados: los árboles reales producen fotos reales, pero las pilas que simbolizan árboles producen fotos no-reales, porque reproducen una no-realidad.

En definitiva -en su discurso- la "realidad de la fotografía" depende de la realidad del referente, es decir, según se ha entendido desde siempre la fotografía, de la realidad de la escena, no del artificio fotográfico. 


\section{Caso 2: Nochebuena 2005, 00.45 hs}

Observo desde la terraza de casa a una pareja en la vereda de enfrente: ella pega saltos en el aire levantando los brazos al grito de "idale, dale!", mientras él intenta infructuosamente captar el salto con una pequeñísima cámara digital, de ésas que han reemplazado a las pocket de rollo en la lista de elementos tecnológicos de adquisición imprescindible para la clase media en los últimos años. Se trata de un artefacto que tiene el aura de "tecnología de última generación", lo que implica, en el imaginario generalizado, que se trata obviamente de una mejora en relación a la "vieja tecnología". Indefectiblemente, el flash se dispara siempre un segundo después de que ella termina el salto. Resulta claro que la pareja no sabe que en este tipo de cámaras "económicas" existe un retardo temporal significativo entre el momento del disparo y la captura de la imagen. Intentan varias veces, sin saberlo y sin éxito, repetir el gesto histórico protagonizado por Frank Lakama cuando obtuvo la fotografía que se conoce como una de las primeras "instantáneas" de la historia, hecha en marzo de 1888 a bordo del paquebote "La Gascogne".

\section{Caso 3: La obsesión de Antonino Paraggi ${ }^{3}$}

En su relato La aventura de un fotógrafo, Ítalo Calvino (1989) nos cuenta las desventuras de Antonino Paraggi, cuyo grupo de amigos, en su mayoría aficionados a la fotografía doméstica, pasaba gran parte del tiempo dedicado a salidas y reuniones registrando fotográficamente todo lo que sucedía. Pero Antonino no compartía en principio este gusto por la fotografía. Su verdadera pasión era, en palabras de Calvino:

Comentar con los amigos los acontecimientos pequeños y grandes, desentrañando de los embrollos particulares el hilo de las razones generales; era, en suma, por actitud mental, un filósofo y ponía todo su amor propio en conseguir explicarse incluso los hechos más alejados de su experiencia. Ahora bien, sentía que algo en la esencia del hombre fotográfico se le escapaba ...

Sin embargo, en algunas ocasiones se veía obligado a "operar" la cámara fotográfica, ya que el grupo se lo pedía cuando quería retratarse como tal. A partir de estas experiencias, Antonino comenzó a esbozar un principio de teoría acerca del significado de los actos (de los fotógrafos y de los fotografiados):

-Porque una vez que has empezado -predicaba-, no hay razón para detenerse. El paso entre la realidad que ha de ser fotografiada porque nos parece bella y la realidad que nos parece bella porque ha sido fotografiada, es brevísimo. (...) Basta decir de algo 'iAh, qué bonito, habría que fotografiarlo!' y ya estás en el terreno de quien piensa que todo lo que no se fotografía se pierde, es como si no hubiera existido, y por lo tanto para vivir verdaderamente hay que fotografiar todo lo que se pueda, y para fotografiarlo todo es preciso: o bien vivir de la manera más fotografiable posible, o bien considerar fotografiable cada momento de la propia vida. La primera vía lleva a la estupidez, la segunda a la locura. (...) El único modo de actuar con coherencia es disparar por lo menos una foto por minuto, desde que abre los ojos por la mañana hasta el momento de irse a dormir. (...) Si yo me pusiera a hacer fotografías seguiría este camino hasta el final, a costa de perder la razón. 
Motivado por estas reflexiones se compró una cámara y, fiel a sus razonamientos, se dedicó a retratar a Bice, una joven de la cual se había enamorado. Juntos tomaron la decisión de convivir y desde ese momento no la dejó en paz ni de día ni de noche en su afán por registrar cada instante de su vida. A tal punto llevó su empresa que, cuando Bice lo abandonó cansada de su obsesión, Antonino se hundió en una crisis depresiva y comenzó a disparar fotos "... compulsivamente mirando el vacío. Fotografiaba la ausencia de Bice". La crisis producida por su separación lo llevó a intentar distintos métodos de fotografiar la realidad, inclusive fotografiando hojas de periódicos que incluían fotos, hasta llegar a descubrir que:

Agotadas todas las posibilidades, en el momento en que el círculo se cerraba sobre sí mismo, Antonino comprendió que fotografiar fotografías era el único camino que le quedaba, más aún, el verdadero camino que oscuramente había buscado hasta entonces.

La actitud extrema y ligada al absurdo de Antonino refleja muy bien una de las prácticas incorporadas en los últimos años en la fotografía -en la doméstica o de aficionados en mayor medida, pero también en la profesional- alentada por los nuevos elementos tecnológicos.

\section{Los modos de representación de lo real y la desmaterialización de la imagen/objeto} Comencemos por prestarle atención al "equívoco" planteado por el alumno del caso 1 entre lo real y su representación, equívoco que proviene de una confusión de vieja data. Para comprenderlo, es necesario remontarse al Renacimiento, momento en que se instaló en la historia de la imagen, o al menos en la de la imagen occidental, una forma de representación de lo real que aspiró al mimetismo, basada en la búsqueda de una reproducción de lo visible de la forma más parecida al modo en que se presenta el mundo ante la percepción del ojo humano. Fue en ese mismo contexto histórico donde apareció la utilización sistemática de dispositivos ópticos para la obtención de imágenes: los gabinetes de perspectiva y el intersector de Alberti, la ventana de Durero o la tavoletta de Brunelleschi, además de los diferentes modelos de cámara oscura ${ }^{4}$. Es decir, aparecieron las máquinas de imágenes, artilugios tecnológicamente sofisticados para la época que, de alguna manera, abrirían el camino para las tecnologías actuales en materia de obtención de imágenes. Si bien en esta instancia aún se necesitaba del accionar físico concreto del pintor/dibujante sobre una superficie para obtener la imagen final, el hecho de que la representación se produjera mediante un aparato modificaría indudablemente la relación del sujeto con la realidad y su representación. Tales máquinas comenzaban a actuar como "prótesis del ojo" (Dubois 2000) que creaban imágenes por sí mismas, en cierta forma de manera autónoma y, por ello mismo, implicaron una modificación de la visión, sobre todo en términos de una supuesta objetividad. La perspectiva artificial, un producto conceptual de la época, una de las posibles visiones de lo real-no olvidemos que perspectiva es una palabra latina traducible como "ver a través de", lo que implica la elección de un punto de vista- se transformaría en la forma natural de representar la realidad. De aquí surgió esta suerte de simbiosis entre lo real y su representación que produce confusiones como la de nuestro alumno: la sensación de realidad que produce la fotografía hace que se sienta obligado a separar las imágenes en función de sus referentes, uno natural y el otro fabricado, porque para su percepción las dos fotos son espejo de lo real.

Pero en aquella instancia de la historia y a pesar de la intervención de una máquina en la concepción de la imagen, el producto final, la pintura o el dibujo, todavía gozaba de una materialidad absoluta 
en tanto objeto físico: era tangible, concreto y transportable.

Con la aparición de la fotografía en el primer tercio del siglo XIX, las máquinas de imágenes tomaron vuelo. La cámara fotográfica, concebida a partir de los dispositivos ópticos anteriormente mencionados, sobre todo de la estructura de la cámara oscura, se convirtió en la primera máquina de imágenes autónoma: ya no se necesitaba al pintor/dibujante, puesto que la fotografía autoinscribía la imagen de lo real sobre un soporte sin la intervención de la mano del hombre. Esta posibilidad se dio a partir de ciertos descubrimientos alrededor de productos químicos capaces de formar e inscribir una imagen al recibir energía lumínica y fijarla permanentemente sobre un soporte. La máquina (fotográfica) se convirtió entonces en la constructora de la imagen, no ya una prótesis del ojo, sino el ojo mismo. En la percepción de la sociedad, el sujeto se transformó en un simple operador de la máquina y ésta en el dispositivo de mediación entre la realidad y su copia, la fotografía.

Y como consecuencia necesaria, surgió la idea de que la reproducción de lo real a partir de este dispositivo era más "objetiva" y que había una conexión casi directa, de contigüidad -del orden del índice según la clasificación que Pierce hace de los signos- entre lo real y su representación. Obviamente se acentuó la noción de espejo de lo real: tan fuerte es esta noción, al menos en el saber común, que en el siglo XXI y en un contexto universitario, surge aún espontáneamente esta naturalización de la fotografía como reproducción de lo real, tal como analizábamos en el caso de la presentación de un trabajo fotográfico.

Pero aunque la máquina de imágenes fotográficas acentuaba la mímesis, el producto obtenido no cambiaba esencialmente su materialidad: la foto seguía siendo un objeto concreto y transportable. De todas formas, había una nueva característica: era reproducible infinitamente, al menos en teoría, a partir de un original, el negativo (interesante denominación para una imagen opuesta a la realidad en términos de valores tonales o cromáticos) Cabe señalar, sin embargo, que esta posibilidad de reproducción raramente fue considerada en la fotografía doméstica, dónde lo valioso era la copia, que funcionaba casi como un original. Volveremos sobre este tópico más adelante.

La invención del cine sobre el final del siglo XIX vino a agregar un nuevo elemento a la imagen de lo real: la temporalidad. Las posibilidades de la instantánea fotográfica surgidas en ese momento -que dieron origen, entre muchas otras, a la fotografía de Lakama mencionada en el caso de la parejita en Navidad - y la consecuente posibilidad de la imagen seriada - fueron desembocando "naturalmente" en la idea de la imagen/movimiento. Ya no sólo era posible reproducir la realidad de manera fija sino que podía agregársele la ilusión de dinamismo y por lo tanto la idea de transcurso temporal.

Ahora bien, esta nueva característica de la representación alteró notablemente la materialidad de la imagen/objeto que prácticamente no había sufrido cambios con el "pasaje" de la pintura a la fotografía: la imagen movimiento existe sólo cuándo es proyectada, la película no está en ninguna parte y necesita de otra máquina (la de proyección) para existir. Si bien es cierto que existe aun un "original" concreto y tangible, compuesto de una sucesión de fotos fijas que pueden verse individualmente, estos fotogramas no son la película en sí.

Con la aparición del video, las máquinas de imágenes se transformaron en algo absolutamente imprescindible no sólo ya para la obtención de la imagen sino además para su visualización misma. Ya no existía el original "visible", ni siquiera en la forma de sucesión de fotos fijas del fílm. Dentro del sistema, la televisión llevó el concepto al límite como paradigma de reproducción de lo real: no sólo reproducía lo real en su apariencia visual (tal como la fotografía), con el agregado del movimiento y la dimensión temporal (como el cine) sino que además podía transmitir a todas partes al mismo tiempo y en directo. Al decir de Dubois (2000) "Se trata de la mímesis del 'tiempo real': el tiempo elec- 
trónico de la imagen está (sincronizado con) el tiempo real".

En este sentido, lo real y su "copia" (su representación) se fusionaron prácticamente en una misma cosa, lo que conllevaba una sensación de verdad no experimentada antes con ningún medio de reproducción de lo visual: "en vivo y en directo" ha sido uno de los slogans más utilizados en este medio para garantizarle al espectador que lo que está viendo es "la realidad misma".

Pero al mismo tiempo comenzó a concretarse la desmaterialización de la imagen/objeto de una manera violenta: la luz, materia prima en la formación de la apariencia visual de lo real, se transformaba ahora en impulsos eléctricos para ser almacenada y debía traducirse nuevamente a impulsos lumínicos para ser vista. La imagen ya no existía como objeto, sino sólo como información registrada y transmitida. Sin las máquinas de imágenes la imagen desaparecía, aunque la sensación de que aún era tangible y transportable siguiera existiendo. Paralelamente, tanto el cine como el video colaboraron activamente en el refuerzo de la naturalización del punto de vista renacentista como mímesis de lo real.

Esta escalera tecnológica -que hasta el momento no había descartado ninguno de sus escalones sino que los había ido sumando uno tras otro- llega hoy, con la posibilidad de captura, reproducción y creación digital de imágenes, a un nuevo estadío consistente en la denominada realidad virtual.

La misma curiosa paradoja de su denominación da qué pensar: Según la vigésima primera edición del Diccionario de la Real Academia de la Lengua (1992) "la palabra virtual, proveniente del latín virtus (fuerza, virtud), alude como adjetivo a lo «que tiene virtud para producir un efecto, aunque no lo produce de presente [...] usándose frecuentemente en oposición a efectivo o real». En una segunda acepción "virtual es equivalente a «implícito" $y$ «tácito", teniendo otra significación en la física, donde alude a aquello "que tiene existencia aparente y no real»".

La tecnología de imagen digital se basa, en términos generales, en el mismo principio del video: la apariencia visual de lo real se traduce en información (numérica en este caso) para ser almacenada y nuevamente traducida a impulsos lumínicos que serán visualizados en una pantalla (monitor). Pero esta nueva forma de reproducción de lo real agrega un nuevo elemento: al ser almacenada en forma numérica (dígitos), la imagen es factible de ser modificada -y por supuesto creada- a partir de cálculos.

Esta nueva forma de representación de lo real incorpora además - tal vez para que la contradicción implícita en su misma denominación no desaliente al usuario- algunos elementos nuevos en su representación: la posibilidad de percibir sensorialmente esa "realidad ficticia". A la representación de la apariencia visual se suman en este caso sensaciones táctiles y cinestésicas. Citando otra vez a Dubois (2000), "la impresión de realidad es reemplazada por la impresión de presencia". Este sistema, cuyas imágenes tienen su origen generalmente en impresiones captadas de la realidad, transformadas luego a partir de las posibilidades de la imagen digital con procesos que van desde leves retoques hasta alteraciones sustantivas e incluso, como decíamos antes, creación de nuevas realidades, termina por desmaterializar absolutamente la imagen/objeto. La imagen en muchos casos no existe ni siquiera como información grabada, ya que la inscripción de la misma, por ejemplo en una cámara fotográfica de captura digital, es en principio sólo temporal y puede o no ser guardada luego permanentemente como información recuperable a largo plazo. Se trata más de un proceso que de la creación de una imagen en sí. Y, paradójicamente, cuando la imagen objeto se desmaterializa por completo, se intenta por todos los medios posibles que el espectador pueda ver -con el mayor "realismo" posible- y hasta tocar esa imagen que no existe. Esta nueva forma de representación de lo real va en camino a convertirse en una suerte de "prótesis de los sentidos" (Dubois 2000).

Por otra parte, aunque la imagen no sea ya un objeto, parece ser que no sólo es transportable sino que es posible enviarla a distancia y puede aparentemente reproducirse, aunque no exista, en principio, 
un original a reproducir.

Este desarrollo histórico ha sido acompañado obviamente por un cambio -o más bien una acentuación- de la percepción de lo real y su representación a partir de los diferentes sistemas propuestos por las máquinas de imágenes. Siguiendo siempre en la línea comenzada con las prótesis del ojo, la búsqueda final de todas estas tecnologías sigue siendo la "reproducción mimética de lo visible (y lo táctil y lo audible, podríamos agregar), al menos de la forma más parecida a como se presenta el mundo a la percepción del ojo ( $y$ el tacto y el oído) humano"). A tal punto este camino es el mismo, que una de las obsesiones de la industria informática es producir imágenes -fotográficas, cinematográficas y de video- tan buenas como las tradicionales. Esto implica reconocer, aunque elípticamente, que las nuevas tecnologías necesitan refrendar sus pergaminos comparándose con las tecnologías tradicionales, lo que nos hace sospechar que la "innovación" en este campo es, por lo menos, dudosa.

Entonces cabe preguntarse cuál es, en este desarrollo tecnológico, la especificidad de innovación. Según West y Farr (1990) "Innovación es la secuencia de actividades por las cuales un nuevo elemento es introducido en una unidad social con la intención de beneficiar la unidad, una parte de ella o a la sociedad en conjunto. El elemento no necesita ser enteramente nuevo o desconocido a los miembros de la unidad, pero debe implicar algún cambio discernible o reto en el status quo." (el subrayado es nuestro). Si nos guiamos por esta definición y consideramos que en este campo, el de la imagen, todo marcha siempre en la misma dirección y nada ha cambiado sustancialmente desde la cámara oscura renacentista hasta la generación de "realidades virtuales" por computadora -excepto la dependencia tecnológica-cabría preguntarse si las innovaciones no serán sólo una cuestión de ampliar mercados a través del recambio tecnológico para seguir haciendo lo mismo de siempre pero con máquinas nuevas, que algunas veces ni siquiera son nuevas.

Sin embargo, y aunque tal vez no sea el objetivo primordial del desarrollo tecnológico producido alrededor de la imagen, las nuevas máquinas de imágenes van generando cambios en la cultura y, ya que desde nuestra posición en el mundo raramente podemos ser generadores de tendencias, deberíamos al menos prestarle mucha atención a los efectos que estas olas tecnológicas van produciendo en nuestra sociedad. Lo que le sucede a la pareja descripta en el caso 2 tiene que ver con esto: lo que ellos están tratando de hacer (sin éxito) con su cámara digital -tecnología de "última generación" según el supuesto implícito de la publicidad- fue realizado (con éxito) hace más de cien años, con una cámara que hoy es una pieza de museo que se mira, en el mejor de los casos, con el cariño y la sonrisa paternal con que se recuerdan los primeros pasos de un niño que se ha convertido en adulto. Sin embargo ellos, los protagonistas del caso citado, seguramente adhieren como la mayoría -incluidos muchos profesionales de la imagen- al preconcepto sustentado por el mercado de que todo "nuevo producto" siempre es un paso hacia delante en el progreso, que siempre y sin lugar a dudas la última tecnología es mejor que la anterior y que hay que poseerla si no queremos quedar "fuera de la historia". En este caso en particular está claro quienes son los que quedan fuera de la historia.

Los recambios tecnológicos se producen con tanta velocidad que resulta difícil saber hasta qué punto benefician o no a los usuarios. Cuando aún no se ha podido definir completamente la influencia que ha tenido -y tiene- la imagen en la sociedad, ya estamos hablando de imagen digital, como si la historia de la imagen fotográfica fuera sólo una cuestión de reemplazar tecnologías -y denominaciones-a medida que otras más nuevas aparecen. En todo caso, lo que habría que revisar más en profundidad es el concepto de representación y mímesis, de lo real y su espejo, que sigue siendo el tema importante. En este sentido, deberíamos analizar si estas nuevas tecnologías pueden modificar el paradigma de la imagen y su poder de representación de lo real. Retomaremos este tema al final del artículo. 


\section{Imagen y memoria}

Creemos que el caso de Antonino, aunque ficticio, grafica bien uno de los usos más extendidos que se le ha dado a la imagen a partir del siglo XIX: el registro documental, ligado directamente con el poder de mímesis de las máquinas de imágenes. Junto con el desarrollo de la imagen como representación de lo real a lo largo de los siglos y sobre todo a partir de la aparición de la imagen fotográfica, la sociedad en general y los individuos en particular han utilizado las máquinas de imágenes para producir archivos y documentar casi todo. Desde su nacimiento -y en los primeros años de existencia casi exclusivamente- la fotografía asumió la tarea de convertirse en generadora de documentos visuales del mundo para dejar a las futuras generaciones un archivo de lo que ya no podrían ver de otra forma porque sería destruido en pos del progreso. Así se dedicó una increíble cantidad de material fotográfico al registro de paisajes, construcciones, modas y costumbres que se sabía, o al menos se presentía, no perdurarían por mucho tiempo. Al decir de Ernest Lacan (citado por Michel Frizot, 1989):

La fotografía realiza su obra en todos lados. Registra vuelta a vuelta sobre sus tabletas mágicas los acontecimientos memorables de nuestra vida colectiva, y cada día enriquece con algún precioso documento los archivos de la historia.

En una interesante reflexión alrededor del papel de la fotografía en la historia que, tal vez, nos pueda dar una pista sobre el porqué del desarrollo de la actividad de registro, dice John Berger (1998) en su libro Mirar:

¿Qué hacía las veces de la fotografía antes de la invención de la cámara fotográfica? La respuesta que uno espera es: el grabado, el dibujo, la pintura. Pero la respuesta más reveladora sería: la memoria. Lo que hacen las fotografías allí afuera, en el espacio exterior a nosotros, se realizaba anteriormente en el marco del pensamiento. (...) Tanto la lente de la cámara como el ojo, debido a su sensibilidad a la luz, registran imágenes a una gran velocidad $y$ de forma inmediata al acontecimiento que tienen delante. Lo que, sin embargo, hace la cámara, y el ojo por si mismo no puede hacer nunca es fijar la apariencia del acontecimiento. Extrae la experiencia de éste del flujo de otras apariencias y lo conserva, tal vez no para siempre, pero al menos mientras exista la película. La cámara separa una serie de apariencias de la inevitable sucesión de apariencias posteriores. Las mantiene intactas. Y antes de la invención de la cámara fotográfica no existía nada que pudiera hacer esto, salvo, en los ojos de la mente, la facultad de la memoria.

El afán archivista, limitado en primera instancia a los organismos oficiales y realizado casi exclusivamente por profesionales, fue haciéndose una costumbre más general y realizada por individuos a partir de la popularización del uso de las cámaras fotográficas hacia finales del siglo XIX y principios del XX. Sería reiterativo citar la cantidad de notas producidas al respecto, desde artículos periodísticos hasta ejemplos de humor gráfico referidos al tema que se sucedieron a principios del siglo pasado. Luego hubo una especie de impasse, producido tal vez por un acomodamiento de las estructuras de producción de imágenes: los medios a través de sus profesionales (reporteros gráficos, camarógrafos de televisión, cineastas) realizaban el registro visual y los consumidores (todos los demás) se convertían en espectadores, aunque el afán de "archivaje" individual se mantuvo vivo en la fotografía doméstica e inclusive se fue incrementando a medida que las posibilidades de tener 
una cámara fotográfica económica o una cámara de video casero fueron alcanzando cada vez a más estratos de la sociedad. Y en los últimos años este afán archivista se ha exacerbado, creemos, por la aparición de la tecnología de captura digital que no sólo permite sino que induce al registro y archivo compulsivo de imágenes.

Dice Pierre Nora (1989) en su texto Entre la memoria y la historia:

La memoria moderna se da, ante todo, a modo de archivo. Se apoya por completo en la materialidad de la huella, en la inmediatez del registro, en la visibilidad de la imagen. Lo que comenzó como escritura terminó como alta fidelidad y grabación de cinta. El temor a una desaparición rápida y final se combina con la ansiedad con respecto al significado del presente y a la incertidumbre en cuanto al futuro, para otorgarle incluso al más humilde testimonio, al más modesto vestigio, la dignidad potencial de lo memorable. Lo que llamamos memoria es de hecho el gigantesco y sobrecogedor depósito de reservas materiales de todo aquello que nos sería imposible recordar, un ilimitado repertorio de todo aquello que podría necesitarse para ser rememorado. Ninguna sociedad ha producido nunca archivos de un modo tan deliberado como la nuestra, no sólo en cuanto a su volumen, no sólo merced a los nuevos medios técnicos de reproducción y preservación, sino también por su admiración supersticiosa, por su veneración de los vestigios. Inclusive a medida que desaparece la memoria tradicional, constantemente nos sentimos obligados a coleccionar residuos, testimonios, documentos, imágenes, disertaciones, cualquier signo visible de lo que ha sido, como si fuese necesario apelar a este prolifico dossier para presentar alguna prueba ante quién sabe qué tribunal de la historia. Registra todo lo que puedas, algo permanecerá.

Esta última frase parece ser la clave del tema, no se sabe por qué, ni para qué, pero hay que registrar. La compulsión fotográfica de Antonino Paraggi parece ser nada más que una hipérbole, una puesta en absurdo de lo que en mayor o menor medida nos sucede a todos.

$\mathrm{Y}$ es en este punto dónde se juntan las máquinas de imágenes de tecnología digital y la desmaterialización de la imagen/objeto con el archivo como sustituto de la memoria, para dar pie a algunas reflexiones y preguntas -más que nada preguntas- sobre el momento presente de la imagen y la postura que deberíamos adoptar aquellos que estamos involucrados de una u otra manera-desde la creación, la docencia o el pensamiento- con el mundo de las imágenes.

\section{Algunas preguntas}

La tecnología de captura digital de imágenes está produciendo en la sociedad un fenómeno similar al acaecido en el momento de la aparición de las cámaras compactas de uso popular: una superproducción de imágenes -fotográficas en su mayoría - que se nota particularmente en la fotografía denominada doméstica (aquella producida por individuos no profesionales y generalmente realizada en ámbitos privados), aunque en esta ocasión el fenómeno alcanza también a gran parte de la fotografía profesional, sobre todo a la que tiene que ver con los medios gráficos y/o electrónicos de noticias. Todo se registra, todo es potencialmente interesante y aunque más no sea por las dudas, es preferible registrarlo.

La cámara digital, confesado esto por varios colegas, profesionales de la fotografía, produce una suerte de "invitación al disparo", una "incontinencia en la captura" que lleva inevitablemente a una 
superabundancia de imágenes. Esta superproducción es alentada inclusive por la tecnología, que genera funciones ad hoc que hubieran sido de gran ayuda para el plan de Antonino Paraggi. Reza un anuncio de cámaras digitales en www.camarasdigitales.com:

(la empresa X) acaba de anunciar el lanzamiento de una nueva serie de cámaras, la serie $P$, que se caracteriza por tratarse de unas máquinas dirigidas fundamentalmente al usuario avanzado, aunque sin dejar a un lado la simplicidad de uso.

(...) Pero al margen de lo indicado, debe mencionarse también que ambas máquinas cuentan con todo tipo de ajustes manuales, conexión para Flash externo, pueden grabar las imágenes en formato RAW y en formato TIFF, además por supuesto de hacerlo en el habitual JPG, tienen una elevada velocidad de proceso, y cuentan hasta incluso con intervalómetro para programar la realización automática de 2 a 99 fotografías a intervalos de 10 segundos a 24 horas. (los subrayados son nuestros)

Es interesante ver cómo el término cámara, que alude directamente al espacio oscuro imprescindible para la formación de la imagen y que deriva de la cámara oscura renacentista, fue reemplazado a lo largo de la historia por el término más general máquina. En este pasaje lingüístico se va dejando de hacer referencia al funcionamiento primario de un dispositivo en particular, con un nombre que invita a la indagación y la pregunta - ¿por qué cámara oscura?- para ir incluyéndolo en una categoría más general, la de las máquinas, aparatos que por definición y costumbre vienen a sustentar el progreso de la humanidad, a facilitarle las tareas al individuo. Sobre este punto también se hace hincapié en la publicidad: máquinas para usuario avanzado pero con "simplicidad de uso". Pero ¿a que uso se refiere? Por supuesto al que tiene que ver con lo operacional, nunca con el uso en el sentido más profundo del término ¿Para qué tomo fotos? ¿Cuándo vale la pena sacarlas? ¿Qué propósito tiene hacer 99 fotografías a intervalos de 10 segundos o de 24 horas? Hemos escuchado el caso reciente de un dibujante, fotógrafo aficionado (podría ser nuestro caso 4), que en un viaje de quince días por el norte de Argentina registró, literalmente, ¡10.000 fotografías! ¿Se habrá planteado en algún momento el tiempo que necesitaría luego para visualizarlas y elegir las que valía la pena tener? No, evidentemente, porque por lo que sabemos es el problema irresoluble con el que se encuentra ahora, a la vuelta de su viaje: no tiene tiempo para editar lo que sacó.

Está claro que la industria apuesta a lo digital, que la producción de imágenes no es una excepción en la lógica del mercado y que quien no se "suba a la ola tecnológica dominante" probablemente quede excluido del medio ${ }^{5}$. De hecho, una de las empresas multinacionales más grande de fotografía ha discontinuado la fabricación de papel fotográfico blanco y negro a partir de diciembre de 2005 y ha puesto toda su energía en la producción de insumos para el sistema digital. ¿Significa esto que la tecnología de impresión digital es superior, de mayor calidad, más duradera que la impresión tradicional sobre papel de gelatina de plata? Lo dudamos, pero la industria necesita cambiar los sistemas para acrecentar el consumo. Aparentemente no podemos generar nuestras propias condiciones de trabajo ni decidir los materiales que usaremos, dado que unas y otros son dictados desde algunos centros de poder económico que deciden cual tecnología se debe utilizar y cuál no. Tratemos entonces por lo menos de estar atentos para extractar los elementos positivos y rechazar los negativos a partir de las reflexiones que podamos producir.

Sería interesante a esta altura y dado este contexto, poner sobre el papel algunos elementos extractados de nuestra experiencia práctica como fotógrafos y docentes para analizar este momento y tratar de entenderlo. 
Una de las tareas básicas del fotógrafo en el trabajo con cámaras tradicionales -llamaremos así a las cámaras que funcionan con el sistema óptico/químico de registro- tiene que ver con el encuadre y la elección del momento del disparo. Estas operaciones actúan, durante la toma, como una suerte de discriminación acerca de qué cosa y en qué momento vale la pena de ser fotografiada. La lógica de la economía de dinero (el costo del material sensible) y del tiempo (el proceso posterior a la toma necesario para obtener el negativo y luego la copia) generaban en la gran mayoría de los fotógrafos -tanto profesionales como aficionados consuetudinarios- una suerte de ejercicio de decisión, a veces casi reflejo, a veces más meditado, que se ponía en práctica cada vez que aparecía la tentación del disparo. Con las cámaras de captura digital, el ejercicio de decisión se va relajando. Ya no hay costo en dinero, aparentemente, por cada foto tomada -recordemos que la imagen/objeto no existe más, sólo se trata de impulsos lumínicos traducidos a un código numérico sobre una tarjeta de memoria reutilizable- y el proceso posterior es veloz: ya no hay sistema negativo/positivo, la imagen se ve inmediatamente "igual a la realidad". Estas modificaciones en la captura y visualización de las imágenes, decíamos antes, conducen en la mayoría de los casos a la acumulación indiscriminada de fotografías. Pero, cuando se pierde la capacidad de discriminar qué cosa es memorable, entonces se comienza a registrar todo y con eso lo único que se consigue es trasladar el problema hacia adelante:

Si no se decide con precisión en el momento de la captura qué es lo fotografiable, deberá decidirse en el momento de la visualización y/o edición del material. El resultado final de este proceso es, en el mejor de los casos, fotografiar indiscriminadamente todo -siguiendo la línea de trabajo de Antonino Paraggi- para luego ver ese material como si fuera la realidad y allí sí, aplicar algún criterio de selección a las imágenes obtenidas, es decir casi repetir el gesto del personaje de Calvino al final del relato, casi como "fotografiar fotografías".

Pero este fenómeno de incontinencia produce una situación en el área de la fotografía doméstica que tal vez sea más interesante para generar reflexión, porque tiene que ver con uno de los usos más difundidos de la fotografía, el de crear archivos individuales, o en todo caso familiares, de la memoria. Hemos notado que las personas que poseen una cámara de captura digital desde hace ya algunos años producen fotografías y las archivan, pero no las miran salvo en el momento de la toma: la superproducción de imágenes desalienta cualquier intento de selección posterior -tarea que es una obligación para el profesional que debe entregar su trabajo- Y, como la impresión de todas las imágenes producidas es prácticamente imposible (aquí aparece otra vez el tema del tiempo y, sobre todo del costo), las fotos quedan archivadas en el disco rígido de una computadora o en un CD y prácticamente nadie las vuelve a ver.

Cuando estaba extendido el uso de cámaras tradicionales para el registro de los acontecimientos de la vida dignos de ser recordados, la secuencia del proceso era aproximadamente así: se sacaban las fotos, se mandaban a revelar y al cabo de un par de días o un par de horas se recibía de regreso las copias (las fotos, el objeto importante) y además el negativo. Este último era generalmente guardado en algún cajón y no volvía a revisarse. Lo que tenía "existencia real" era la foto (la copia), esa imagen/ objeto tangible que se transformaba casi en un fetiche, compartido y repetidamente extraído de su lugar de conservación -generalmente un álbum-para volver a ser revisado. Inclusive su pérdida o deterioro generaba algunas angustias y la capacidad de reproducción al infinito a partir del negativo no era prácticamente tenida en cuenta por el usuario. Es más, en la mayoría de los casos no se sabía muy bien dónde estaba guardado el negativo, ni tampoco era esto preocupante: mientras la foto/objeto existiera, la imagen era visible y por lo tanto existía el recuerdo del momento registrado. Recordamos, muchas veces hasta nuestra propia vida, a través de las imágenes que de ella se han registrado. 
La imagen fotográfica aparecía entonces como una prótesis de la memoria.

Hoy, paradójicamente, no hay negativo - ¿se seguirá usando esta denominación en el futuro para la imagen "aún no impresa" como se sigue usando el termino "copia" aunque la impresión digital no parte, en principio, de ningún tipo de original?--, pero las imágenes se guardan en el disco rígido y en muchos casos se olvida en qué "cajón" ${ }^{6}$ (carpeta) se guardaron y pasan a ser lo que antes era el negativo: una imagen que alguna vez obtuvimos y que ahora sólo recordamos vagamente porque no existe como objeto visible, porque no tenemos la copia.

En definitiva y a través de esta práctica digital, la fotografía -y sabemos que tal vez resulte una exageración- prácticamente deja de existir como tal para convertirse en memoria (dejó de ocupar el lugar de, al decir de Berger (1998), para ser) -es decir olvido potencial-, casi tan intangible y difícil de recuperar como las imágenes almacenadas en nuestro cerebro.

La imagen producida por la cámara digital se ve inmediatamente, al igual que la imagen captada por nuestros ojos. Si es memorable se guarda en la tarjeta de la cámara y se pasa luego a la computadora, una especie de memoria a largo plazo. Generalmente queda guardada allí y, dada la enorme cantidad de imágenes que se producen y acumulan, no vuelve a verse. La producción de imágenes, su acumulación y ordenamiento en archivos digitales ocupa tanto tiempo que queda poco margen para volver a revisar el material obtenido, con lo que, la mayoría de las imágenes producidas existen sólo en la memoria. Pero no de quien las tomó, quien podría ocasionalmente regocijarse con el recuerdo de ellas, sino en la memoria del disco rígido de la computadora ${ }^{7}$.

Tal vez una de las cosas que debamos aprender en esta nueva era tecnológica es el viejo arte de la edición, o lo que es lo mismo, volver a generar un criterio para saber cuáles imágenes vale la pena guardar. Y además aprender a practicar la abstinencia: no dejar que la posibilidad de hacer miles de fotos nos obligue a hacer miles de fotos.

Por otra parte podríamos remarcar también que, paralelamente, tal vez la divulgación y el uso extendido de los programas de captura, retoque y generación de imágenes digitales esté minando la credibilidad de la reproducción, develando de alguna manera el origen cultural de la ficción de la representación. Hoy todos sabemos que las tapas de las revistas de actualidad son retocadas con photoshop, sobre todo cuando reproducen (¿reproducen?) la imagen de alguna diva. Si la imagen puede retocarse infinitamente o crearse enteramente a partir de información binaria, ¿Seguirá siendo paradigma de "espejo de lo real" la imagen producida por una máquina que fuera durante tanto tiempo garantía de objetividad en el saber común? Nuestra hipótesis es que esta práctica cada vez más extendida va minando la credibilidad de la imagen fotográfica, alterando uno de las características más fuertes del medio, lo que Barthes (1979) ha definido como el "esto ha sido" que toda imagen fotográfica transmite.

El mercado impone "tecnologías" y nosotros las incorporamos, en la mayoría de los casos, sin la reflexión necesaria. Cada vez en mayor medida, las imposiciones del mercado condicionan las decisiones del usuario, cada vez hay menos posibilidad de elección. Dejan de fabricarse algunos productos de uso habitual y las nuevas tecnologías en este nuevo siglo van desplazando a las anteriores en lugar de complementarlas. Las máquinas de imágenes, en algún punto, no han cambiado sustancialmente desde la cámara oscura hasta la tecnología digital. Pero sí seguramente generan cambios en el paradigma de representación y en los hábitos sociales a través del uso, sea esta su intención original o no. Nos parece entonces que lo importante es estar concientes de en qué punto el uso de las tecnologías y el pensamiento alrededor de ellas puede producir, ahora sí, innovaciones, ya sea en el campo de la estética, de los hábitos sociales o de la creación de sentido. Si no podemos decidir qué tecnolo- 
gías usar porque estamos sujetos a lo que el mercado dispone, debemos poner todo el esfuerzo en "apropiarnos" de dichas tecnologías y profundizar sobre el uso que hagamos de ellas. De esta forma tendremos la seguridad de que, lo que sea que hagamos con las imágenes dependerá de nosotros y no del tipo de tecnología utilizada y podremos construir una visión (una realidad) en la cual -parafraseando a Dubois- la verdadera innovación ${ }^{8}$ estará siempre en manos de los fotógrafos, nunca en manos de los fabricantes.

\section{Notas}

1 Esta frase que hago mía para justificar el desparpajo de pretender hacer teoría sobre la imagen, fue extractada de una reflexión de Minor White (1908-1976), fotógrafo norteamericano, partidario de la "straight photography", discípulo de Stieglitz y uno de los fundadores de la revista Aperture, de la que fuera editor por varios años. $\mathrm{N}$ del A

2 La foto en cuestión se titula "Recuerdo del viaje realizado a bordo del paquebote "la Gascogne", marzo de 1888" y muestra a un hombre en el "apogeo" de un salto provocado frente a la cámara específicamente para ser fotografiado. N del A

3 Personaje protagonista del cuento La aventura de un fotógrafo del escitor italiano Italo Calvino, incluido en el libro Los amores difíciles. $\mathrm{N}$ del $\mathrm{A}$

4 Para más detalles sobre estos dispositivos ver la obra de Eric Renner: Pinhole Photography. Redisconvering a Historic Technique. $\mathrm{N}$ del A

5 Dice otra publicidad de cámaras digitales: "Ya es una realidad la conexión inalámbrica Wi-Fi en el mercado de consumo. (La empresa X) acaba de anunciar el lanzamiento de dos nuevas cámaras digitales: la (X) Coolpix P1 y la (X) Coolpix P2. (...) Además, ambas cámaras disponen de un zoom óptico 3,5x, un potente modo macro que enfoca a tan sólo $4 \mathrm{~cm}$, así como una estética muy cuidada, algo habitual en este fabricante. En resumen, que si quiere estar "a la última" debe tener muy en cuenta estas dos nuevas cámaras digitales." (Los subrayados son nuestros) $\mathrm{N}$ del A

6 Viene a la memoria en este momento una famosa analogía utilizada por los que "sabían" de computación a principios de los ' 90 y trataban de hacernos entender a los legos que la máquina "es como un placard dentro del cual los programas pueden generar archivos con la intervención del operador y las carpetas son como cajones en los que uno puede ir guardando esos archivos" En esos cajones (que por cierto no son cajones) se guardan hoy los negativos (que tampoco son negativos) $\mathrm{N}$ del A

$7 \mathrm{Tal}$ vez, y si se mira con optimismo, la captura digital sirva como anclaje para reforzar en nuestro cerebro el recuerdo de aquella imagen que nos pareció digna de ser registrada y el recuerdo de haberla tomado sirva como disparador para extraerla de nuestra memoria y rememorarla. $\mathrm{N}$ del A

8 Dubois dice: "La cuestión mimética de la imagen no está determinada por el dispositivo tecnológico. Se trata de un problema de orden estético. Todo dispositivo puede formalizar la tensión dialéctica entre semejanza y diferencia, analogía y desfiguración, forma y no forma. Es este juego lo que produce innovación, la innovación esencial es siempre estética nunca técnica" (El subrayado es nuestro) $\mathrm{N}$ del A

\section{Referencias Bibliográficas}

Barthes, R. (1997). La Cámara Lúcida, Nota sobre la fotografía. España: Paidós Comunicación.

Berger, J. (1998). Usos de la fotografía. En Mirar. Buenos Aires: Ediciones de la Flor.

Calvino I. (1989). Los amores difíciles. Buenos Aires: Tusquets.

Dubois P. (2000). Máquinas de imágenes: una cuestión de línea general. En: Video, cine, Godard. Buenos Aires: Libros del Rojas: Universidad de Buenos Aires.

Frizot, M. (1989). Histoire de voir I De l'Invention de l'Art Photographique (1839-1880). París : Photopoche n 40 : Centre 
Nationale de la Photographie. (traducción de Alicia Macias)

(1989). Histoire de Voir II El medio de los tiempos modernos (1880-1939). París : Photopoche $\mathrm{n}^{\circ} 41$, Centre Nationale de la Photographie. (traducción de Alicia Macias)

Nora, P. (1989). Between Memory and History. Les lieux de mémoire. Representations 26. Estados Unidos. The Regents of the University of California. (Traducción de Alicia Macías)

Renner, E. (1999). Pinhole Photography: Redisconvering a Historic Technique. Boston: Focal Press. Butterworth-Heinemann. West, MA y Farr, JL. (1989). Innovation at Work: Psychological Perspectives, Social Behaviour, 4, 15-30.

White, Minor: Rites \& Passages (1978). New York, An Aperture Monograph, Aperture. Disponible en: http://www.camarasdigitales.com

Summary: This work proposes a route through the historical uses of different devices of creation, reproduction and production of images. Through this journey we tried to make a reflection around two topics: the progressive dematerialization of the image as an object and the use of that same dematerialized image like a file element that comes to occupy the place of memory. After this conjunction we tried to elaborate some conclusions about the role of new technologies and its relation to image.

The historical development of modalities of representation and the idea of dematerialization of the image/object leave from some proposals due to Philippe Dubois in Machines of images: a question of main line (2000). From his reading, added to the reading of some other authors -John Berger among them arises the reflection and the hypothesis of the digital photographic capture like a prothesis of memory.

Keywords: memory - photography - prothesis - technology - virtual reality.

Resumo: Este trabalho propõe um percurso através dos usos históricos dos dispositivos de criação, reprodução e produção de imagens. Através deste percurso se pretende fazer uma reflexao ao redor de dois tópicos: a progresiva desmaterialização da imagen como objeto e o uso dela desmaterializada como elemento de arquivo que vem ocupar o lugar da memoria. Da conjunção entre este percurso histórico e as relações antes propostas intenta-se elaborar algumas conclusões sobre o papel das novas tecnologías em relação com a imagem.

O desenvolvimento histórico das maneiras de representação do real e a ideia de desmaterialização da imagen/objeto partem de alguns proponhos propostos por Philippe Dubois em "Máquinas de imagens: uma questão de linha geral"(2000).

Da sua lectura, somada à leitura de alguns outros autores -John Berger entre eles- surge a reflexão e a hipótese da captura fotográfica digital como prótese da memoria.

Palavras chave: fotografia - memória - prótese - realidade virtual - tecnologia. 